\title{
VENTRICULAR SEPTAL DEFECT: THE CLINICAL SPECTRUM*
}

\author{
BY \\ V. SCHRIRE, L. VOGELPOEL, W. BECK, M. NELLEN, AND A. SWANEPOEL \\ From the Cardiac Clinic, Groote Schuur Hospital and Council for Scientific and Industrial Research, Cardiovascular \\ Pulmonary Group, Department of Medicine, University of Cape Town, Cape Town, South Africa
}

Received January 7, 1965

Ventricular septal defect is the commonest congenital cardiac anomaly in our experience. Thus it was encountered in 40 per cent of the 1439 patients suffering from congenital heart disease seen by. one of us in our clinic (Schrire, 1963). It may be isolated, or combined with other malformations such as pulmonary stenosis. The anatomical size, which varies from a pinpoint to almost complete absence of the septum, does not necessarily correlate with the functional size. Because of its site, a large defect may be partially or completely closed by the septal leaflet of the tricuspid valve during ventricular systole. Furthermore, if the defect is in the muscular septum, contraction of the septal muscle during systole reduces its size.

Since the pressure in the left ventricle normally exceeds that of the right, blood shunts from the left to the right ventricle. The resistance offered by a small defect far exceeds the systemic resistance, so that the left-to-right shunt is small. The resistance offered by a large defect is less than the systemic resistance, permitting a torrential left-to-right shunt unless certain adaptations occur. These are an increase in the pulmonary arterial resistance or obstructive overdevelopment of the right ventricular outflow tract. Thus the clinical picture always depends on the size of the defect and the pulmonary resistance, the latter including both pulmonary arterial and infundibular or valve obstruction.

In this communication we present our findings in 160 of 200 consecutive fully-studied patients with ventricular septal defects. The $\mathbf{4 0}$ subjects in whom there was an associated infundibular or pulmonary valve gradient of over $15 \mathrm{~mm}$. $\mathrm{Hg}$ have been excluded. Patients with complex cyanotic heart disease and patients with endocardial cushion defects have not been considered in this study.

We believe that careful clinical examination, together with the electrocardiogram and radiological examination, can provide a reasonably accurate hæmodynamic diagnosis, seldom in conflict with the findings at cardiac catheterization.

\section{SUBJECTS AND MeTHOdS}

All patients were seen and studied in the Cardiac Clinic, usually on several occasions, special attention being paid to auscultation, as previously described (Vogelpoel and Schrire, 1955). At first, a diagnosis of ventricular septal defect only was entered, but with increasing experience an attempt was always made to predict the nature of the hæmodynamic disturbance from the clinical findings and to confirm this with a cardiogram and radiograph. Radioscopy was routinely performed in the Clinic by one of us (V.S.) and radiography independently in the radiological department. Sound tracings before and after amyl nitrite inhalation (Vogelpoel et al., 1959) were available in almost all the subjects.

\footnotetext{
*Part of the expense of this study has been defrayed by grants from the Council for Scientific and Industrial Research and the City Council of Cape Town.

Presented at the 3rd Asian-Pacific Congress, Kyoto, Japan, May 1964.
} 
TABLE I

Age and Sex in 160 Patients with VSD

\begin{tabular}{c|c|c}
\hline Decade & Male & Female \\
\hline $0-9$ & 48 & $46(2)$ \\
$10-19$ & 23 & 25 \\
$20-29$ & 4 & 6 \\
$30-39$ & 3 & 3 \\
$40-49$ & & 1 \\
$50+$ & 78 & 1 \\
\hline & & 82 \\
\hline
\end{tabular}

Figure in parenthesis is under 1 year.

The diagnosis was proven by cardiac catheterization in 200 consecutive patients. With the development of diagnostic techniques, oximetry, dye dilution curves with indocyanine green, biplane- or cine-angiography have become routine and provide a more accurate assessment of the hæmodynamic disturbances present. Surgical confirmation and measurement of defects were available in 57 patients. There were 8 necropsies. The age and sex are shown in Table $I$.

\section{Results}

The pressure and flow data obtained at cardiac catheterization are shown in Fig. 1. The percentage shunt is plotted on the abscissa and the pulmonary systolic arterial pressure (P.S.P.), expressed as a percentage of the systemic systolic pressure (S.S.P.), on the ordinate. By percentage shunt is meant the percentage of pulmonary blood flow derived from the left ventricle; and wherever possible

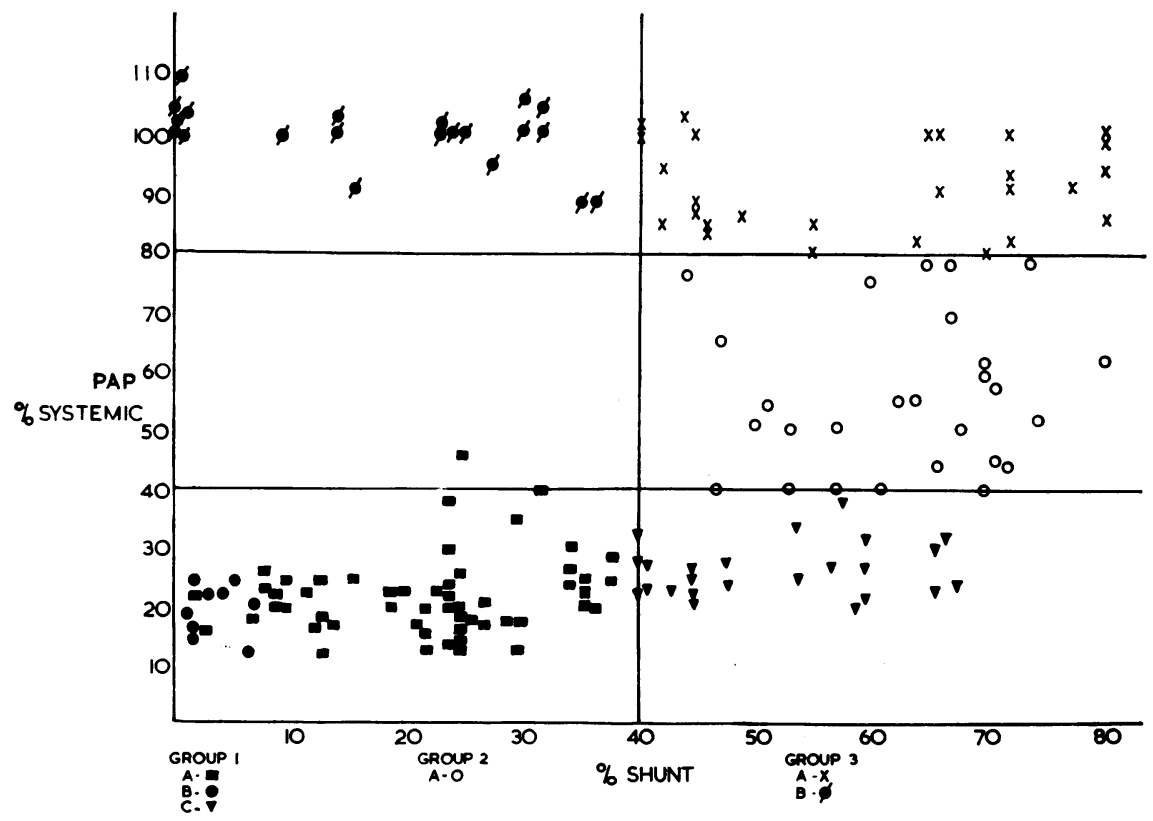

FIG. 1.-The percentage left-to-right shunt in 160 patients with VSD is plotted on the abscissa and the pulmonary systolic arterial pressure expressed as a percentage of the systemic systolic pressure on the ordinate. Three main groups can be recognized on pressure data, Types 1,2 , and 3 , and these can be further subdivided by flow data into Types $1 \mathrm{~A}, 1 \mathrm{~B}, 1 \mathrm{C}$, and 2 , and $3 \mathrm{~A}$ and $3 \mathrm{~B}$ (see text). 
the figures used were those obtained from the Fick principle. These usually tallied fairly closely with the figures obtained by the dye dilution method. Because of much peripheral amplification in brachial or femoral arterial pulse pressure curves, the left ventricular or central aortic systolic pressure was preferred, when available, in calculating the ratio of pulmonary systolic to systemic systolic pressure.

Using the ratio of P.S.P. to S.S.P., ventricular septal defects can be divided into three main groups.

Type 1. Ventricular septal defects with normal or slightly raised pulmonary systolic arterial pressures:

$$
\text { P.S.P./S.S.P. }<40 \text { per cent. }
$$

Type 2. Ventricular septal defect with moderately raised pulmonary arterial pressures:

P.S.P./S.S.P. $\quad 40-79$ per cent.

Type 3. Ventricular septal defect with considerably raised pulmonary arterial pressures:

$$
\text { P.S.P./S.S.P. } 80 \text { per cent and over. }
$$

By using the flow data, ventricular septal defects can be further subdivided, as follows.

Types $1 A$ and $1 B$. Functionally small ventricular septal defects with a left-to-right shunt less than 40 per cent. Types A and B were differentiated solely on auscultatory findings (vide infra), the systolic murmur being short in Type 1A and pansystolic in Type 1B.

Type 1C. Functionally large ventricular septal defect with a left-to-right shunt greater than 40 per cent.

Type 2. Large ventricular septal defects with a left-to-right shunt of more than 40 per cent.

Type 3A. Large ventricular septal defects with a left-to-right shunt of 40 per cent or more.

Type $3 B$. Large ventricular septal defects with a left-to-right shunt of less than 40 per cent, generally with an equal bidirectional shunt or a shunt predominantly right to left.

Type 1. The pressures and resistance were virtually normal in all patients. Only one subject with a small shunt had a pulmonary resistance of 7 units. Amyl nitrite reduced or abolished the left-to-right shunt and phenylephrine increased it (Vogelpoel et al., 1962).

Type 2. The pulmonary arterial pressure was raised in all and the pulmonary resistance varied from normal to 9 units, usually being in the upper range of normal or only slightly raised. Right-toleft shunting was absent. Amyl nitrite and phenylephrine had variable effects but the effect was usually that of Type 1 (Vogelpoel et al., 1962).

Type $3 A$. All patients had a 40 per cent left-to-right shunt or more. A small right-to-left shunt (maximum 20\%) was demonstrated in 5 patients on dye curves. The pulmonary systolic arterial pressure was always raised, the pulmonary resistance varying from normal to 17 units and usually being moderately raised (average 7 units). Amyl nitrite diminished and phenylephrine increased the intensity of the murmur (Vogelpoel et al., 1962).

Type 3B. Pulmonary and systemic systolic arterial pressures were of the same order in all patients. Pulmonary resistance was always high (average 25 units). Bidirectional shunts were present in all patients where adequate studies were available. These were usually balanced, sometimes more left-to-right than right-to-left and sometimes the reverse. The four patients who showed exclusive right-to-left shunts were studied before dye dilution studies and oximetry were available, and small left-to-right shunts may have been missed. Arterial oxygen saturations ranged from 65 to 95 per cent with most patients showing some degree of systemic arterial desaturation. Individual variability was present presumably dependent on the relative resistances of the systemic and pulmonary vascular systems. Manipulation of the resistances with amyl nitrite and phenylephrine showed only minor reactivity so that most of the high pulmonary vascular resistance was regarded as organic (Vogelpoel et al., 1962). Longitudinal studies in three patients in this group with repeat catheterizations showed progressive increase in cyanosis and disappearance of murmurs presumably due to increasing pulmonary vascular resistance. 


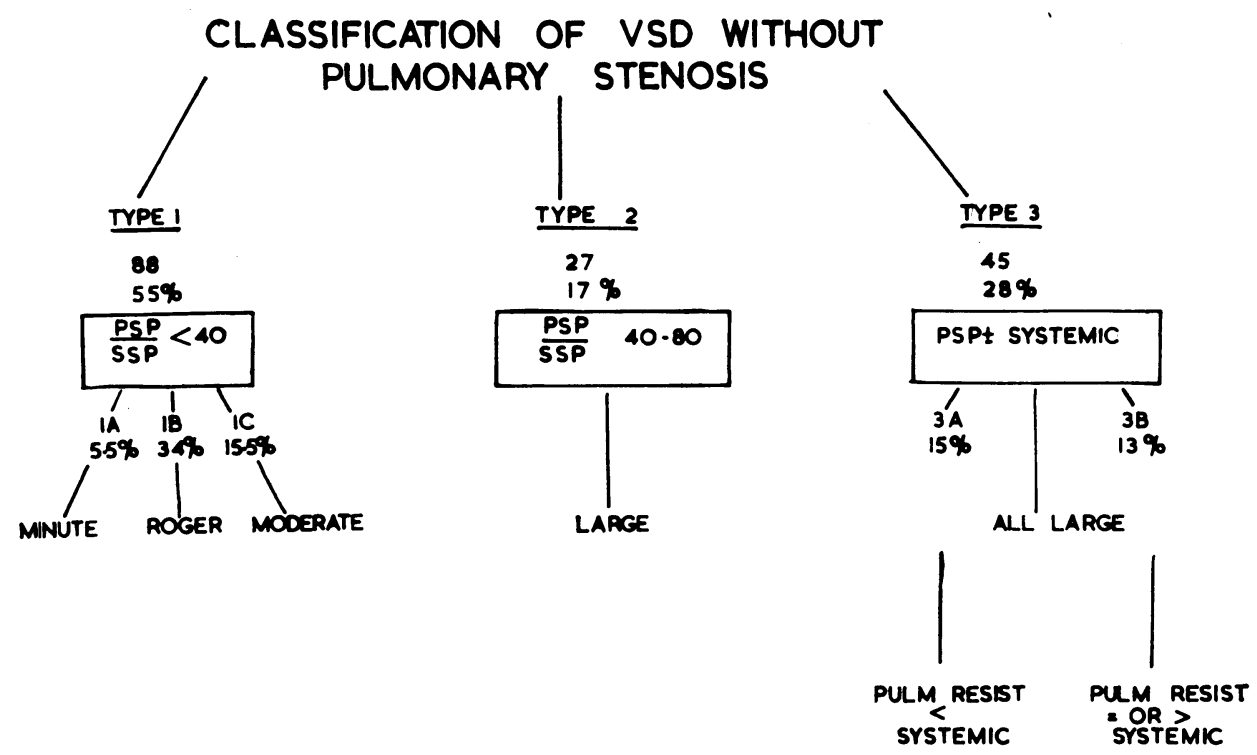

FIG. 2.-Distribution of the various clinical types in the 160 patients with ventricular septal defects.

TABLE II

Age, Sex, Mode of Discóvery of Defect, and Percentage of the Latter Under 1 Year

\begin{tabular}{|c|c|c|c|c|c|c|}
\hline & & $\begin{array}{l}\text { Age range } \\
(\mathrm{yr} .)\end{array}$ & Mean & Male/female & How noted & $\begin{array}{c}\text { Percentage with discovery } \\
\text { under } 1 \text { year }\end{array}$ \\
\hline Type $1\left\{\begin{array}{l}\mathrm{A} \\
\mathrm{B} \\
\mathrm{C}\end{array}\right.$ & $\begin{array}{l}\ldots \\
\cdots \\
\ldots\end{array}$ & $\begin{array}{l}6-14 \\
3-32 \\
1-38\end{array}$ & $\begin{array}{l}10 \\
11 \\
10\end{array}$ & $\begin{array}{l}\text { Equal } \\
\text { Equal } \\
\text { Equal }\end{array}$ & $\begin{array}{l}\text { Murmur } \\
\text { Murmur } \\
\text { Murmur }\end{array}$ & $\begin{array}{l}30 \\
50 \\
60\end{array}$ \\
\hline Type 2 .. & .. & $\frac{3}{12}-32$ & 6 & Equal & Murmur & 80 \\
\hline \multirow{2}{*}{ Type $3\left\{\begin{array}{l}\text { A } \\
\text { B }\end{array}\right.$} & .. & $1-35$ & 9 & Equal & Murmur & 90 \\
\hline & .. & $2-50$ & 16 & Equal & $\begin{array}{c}\text { Murmur; failure } \\
\text { to thrive; cyan- } \\
\text { osis }\end{array}$ & 60 \\
\hline
\end{tabular}

Figure 2 shows the distribution of material according to the aforementioned hæmodynamic classification. There is probably a slight bias in favour of larger defects because not all subjects with smaller defects seen in our clinic were catheterized. A certain amount of overlap between groups is inevitable and anticipated in a condition with as wide a spectrum as ventricular septal defect, for example Type 1C merging with Type 2 and Type 2 with Type 3A. Pulmonary outflow obstruction was found in one-fifth of the patients but this group has been excluded from the study.

Clinical Correlation. The age, sex, and mode of discovery in each type is shown in Table II, the history and physical findings in Tables III and IV, the associated anomalies in Table V, and the surgical findings in Table VI. The clinical findings are evaluated fully in the discussion.

\section{THE EleCtroCARDIOGRAM}

The six standard limb leads and seven præcordial leads V1-V7 were available for analysis in almost all the patients. The mean QRS frontal vectors were plotted as shown in Fig. 3. The 
TABLE III

SYMPTOMS AND DISABILITY

\begin{tabular}{|c|c|c|c|c|c|c|c|c|}
\hline & & & \multicolumn{3}{|c|}{ Percentage in Type 1} & \multirow{2}{*}{$\begin{array}{l}\text { Percentage in } \\
\text { Type } 2 \text { (27) }\end{array}$} & \multicolumn{2}{|c|}{ Percentage in Type 3} \\
\hline & & & A (9)* & B (54) & C (25) & & A (24) & B (21) \\
\hline $\begin{array}{l}\text { Asymptomatic .. } \\
\text { Fatigue .. } \\
\text { Effort dyspnea } \\
\text { Palpitations } \\
\text { Angina pectoris } \\
\text { Cyanosis } \\
\text { Proneness to respi } \\
\text { Grade } 2 \text { disability }\end{array}$ & $\begin{array}{ll}. & . \\
. . & . \\
. . & . \\
. . & . \\
. . & . \\
\text { ory infection } \\
\text { more }\end{array}$ & $\begin{array}{l}. . \\
\ldots \\
\ldots \\
\ldots \\
\ldots \\
. . \\
. .\end{array}$ & $\begin{array}{r}100 \\
0 \\
0 \\
0 \\
0 \\
0 \\
0 \\
0\end{array}$ & $\begin{array}{r}72 \\
20 \\
15 \\
0 \\
0 \\
0 \\
15 \\
2\end{array}$ & $\begin{array}{r}68 \\
16 \\
16 \\
12 \\
0 \\
0 \\
28 \\
8\end{array}$ & $\begin{array}{r}30 \\
45 \\
48 \\
7 \\
0 \\
0 \\
48 \\
50\end{array}$ & $\begin{array}{r}10 \\
30 \\
33 \\
0 \\
0 \\
12 \\
54 \\
62\end{array}$ & $\begin{array}{r}10 \\
30 \\
90 \\
0 \\
5 \\
50 \\
0 \\
50\end{array}$ \\
\hline
\end{tabular}

${ }^{*}$ Number of patients is given in parenthesis.

TABLE IV

PhYSICAL Signs

\begin{tabular}{|c|c|c|c|c|c|c|c|c|}
\hline & & & \multicolumn{3}{|c|}{ Percentage in Type 1} & \multirow{2}{*}{$\begin{array}{l}\text { Percentage in } \\
\text { Type } 2 \text { (23) }\end{array}$} & \multicolumn{2}{|c|}{ Percentage in Type 3} \\
\hline & & & $A(9)$ & B (54) & C (25) & & A (24) & B (21) \\
\hline 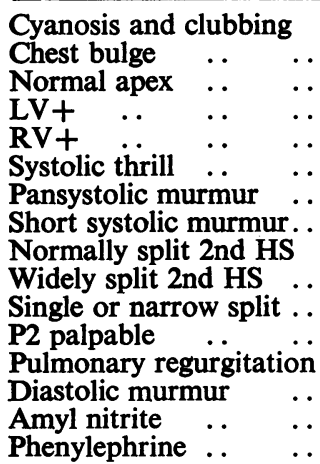 & 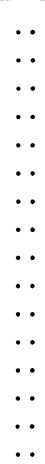 & $\begin{array}{l}\because \\
\because \\
\because \\
\therefore \\
\therefore \\
\because \\
\because \\
\therefore\end{array}$ & $\begin{array}{r}0 \\
0 \\
100 \\
0 \\
0 \\
0 \\
0 \\
100 \\
100 \\
0 \\
0 \\
0 \\
0 \\
0 \\
+\end{array}$ & $\begin{array}{r}0 \\
0 \\
100 \\
0 \\
0 \\
90 \\
100 \\
0 \\
66 \\
34 \\
0 \\
0 \\
0 \\
18 \\
+\end{array}$ & $\begin{array}{r}0 \\
8 \\
50 \\
50 \\
8 \\
96 \\
100 \\
0 \\
64 \\
36 \\
0 \\
0 \\
0 \\
60 \\
+\end{array}$ & $\begin{array}{r}0 \\
30 \\
15 \\
85 \\
63 \\
80 \\
70 \\
30 \\
75 \\
25 \\
0 \\
50 \\
0 \\
80 \\
- \text { or }+ \\
+ \text { or }-\end{array}$ & $\begin{array}{r}0 \\
50 \\
4 \\
96 \\
100 \\
40 \\
45 \\
55 \\
4 \\
0 \\
96 \\
100 \\
38 \\
83 \\
+ \\
-\end{array}$ & \begin{tabular}{|c|}
50 \\
0 \\
0 \\
5 \\
95 \\
5 \\
0 \\
50 \\
0 \\
5 \\
95 \\
100 \\
50 \\
0 \\
No change \\
No change
\end{tabular} \\
\hline
\end{tabular}

TABLE V

Associated MaLFormations

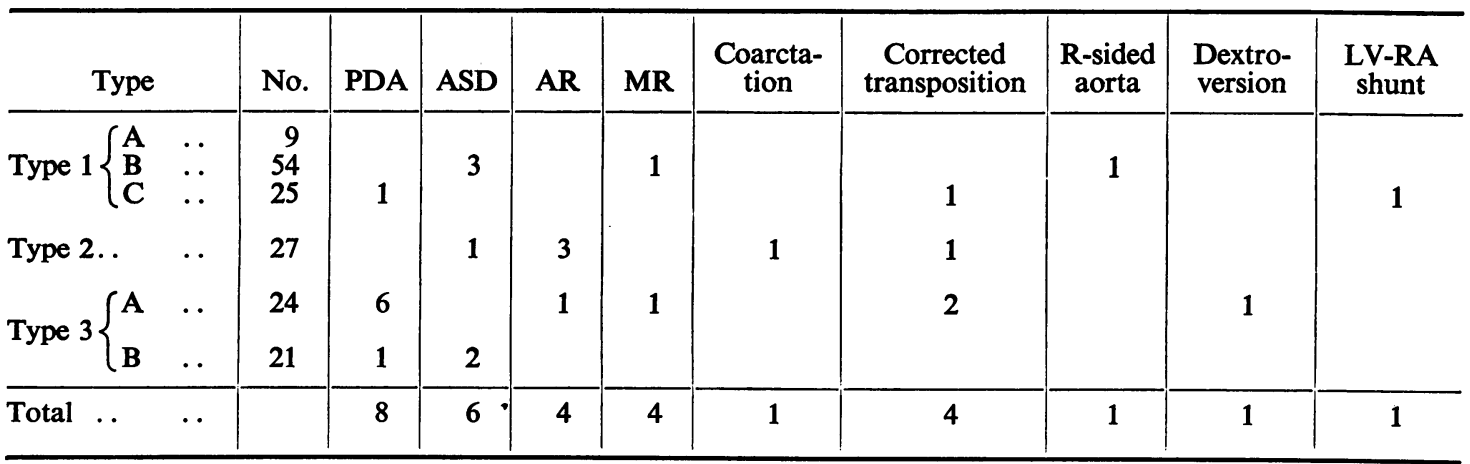


TABLE VI

Size OF DefECT IN THOSE WITH OPERATION

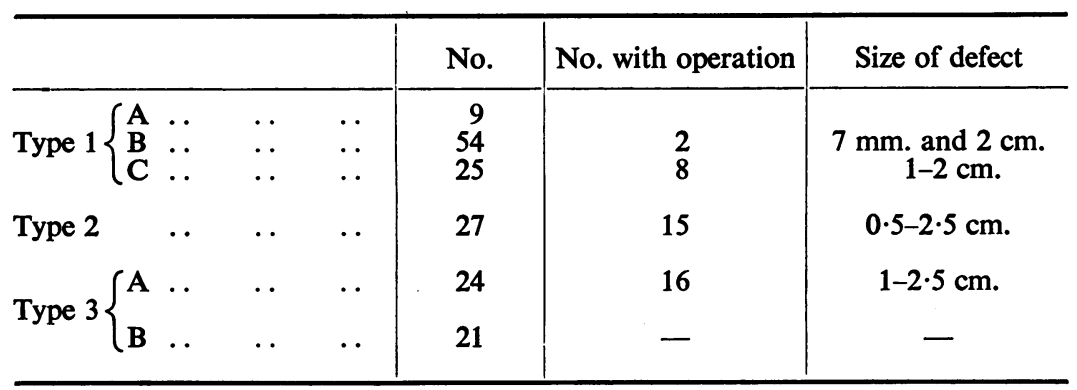

amplitude of the Q, R, and S complexes was measured in V1 and V6, some of the data being presented in Figs. 4 and 5. All tracings were done on the Sanborn direct writer (Visocardiette).

The rhythm was sinus in all but one patient, who had complete heart block. Intermittent A-V dissociation was present in one patient with corrected transposition, and first degree block in 3 subjects with Type 3A defects. The QRS complex was widened to $0 \cdot 12$ sec. in only one patient.

Type 1A. The electrocardiograms were all normal. The mean frontal vector fell in the normal range (Fig. 3) with an anticlockwise loop in most patients.

Type $1 B$. The cardiograms were virtually normal in 80 per cent of the patients: 3 showed right ventricular hypertrophy with an increased $\mathrm{R} / \mathrm{S}$ ratio in $\mathrm{V} 1$ and 7 had incomplete right bundle-branch

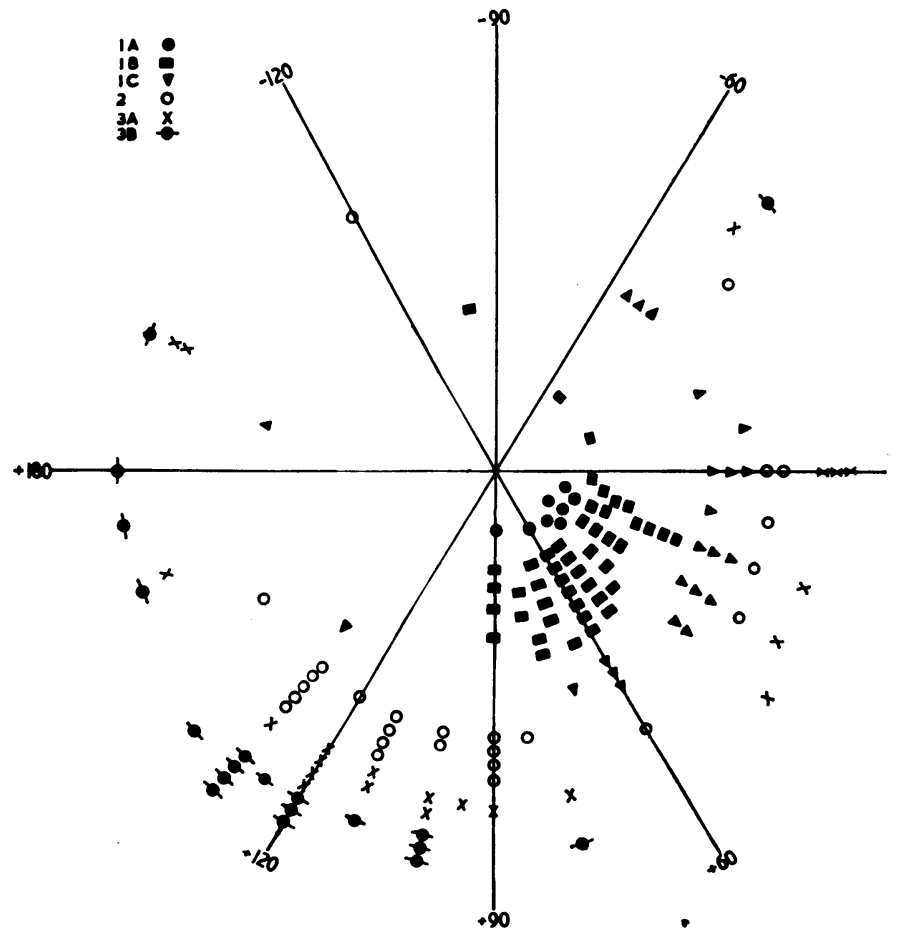

FIG. 3.-The mean QRS frontal vectors have been plotted in the 160 patients with VSD. Right axis duration is almost confined to patients with Types 2 and 3 defects but a normal axis can be found in all groups (see text). 


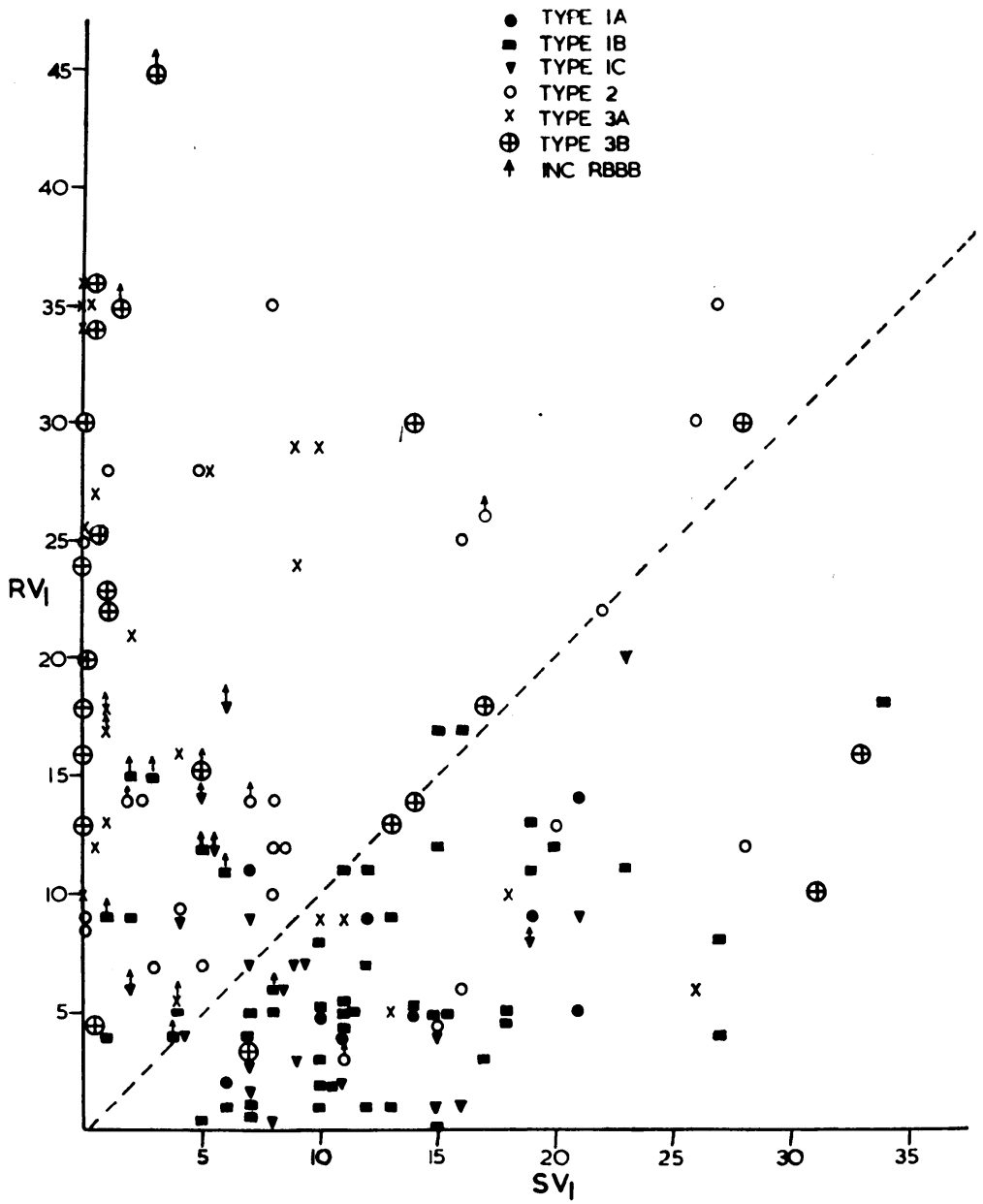

Fig. 4.-The $R$ wave in $\mathrm{mm}$. has been plotted against the $S$ wave in V1. An increased $R / S$ ratio occurs predominantly in Types 2 and 3 but a considerable overlap occurs.

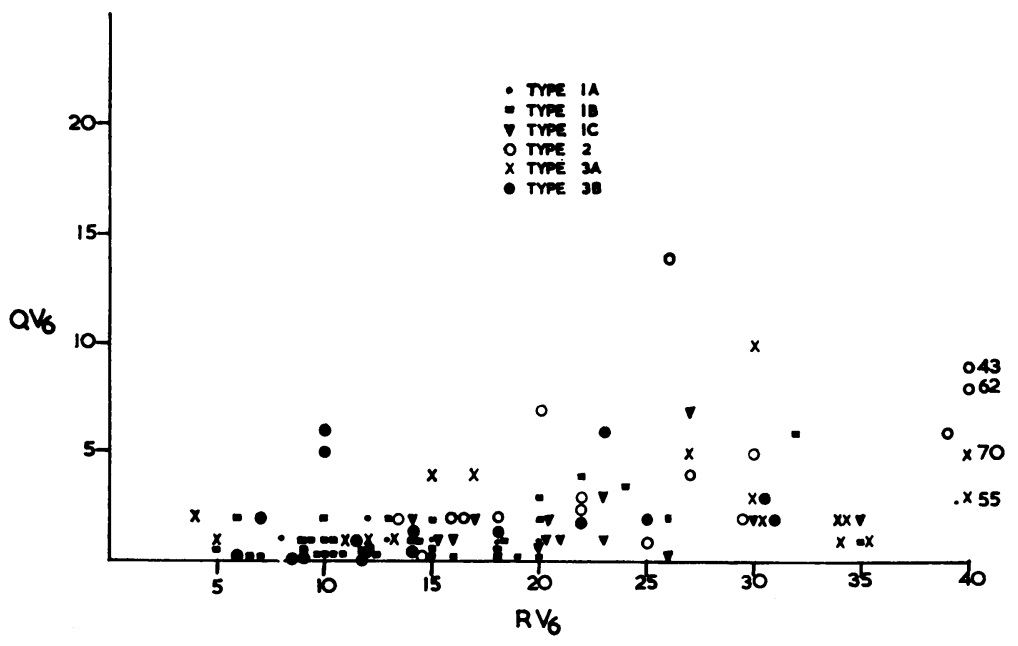

Fig. 5.-The $Q$ wave in $\mathrm{mm}$. has been plotted against the $R$ wave in V6. Both are increased mainly in Types 2 and $3 \mathrm{~A}$ but the overlap is too great for the measurement to have much value. 


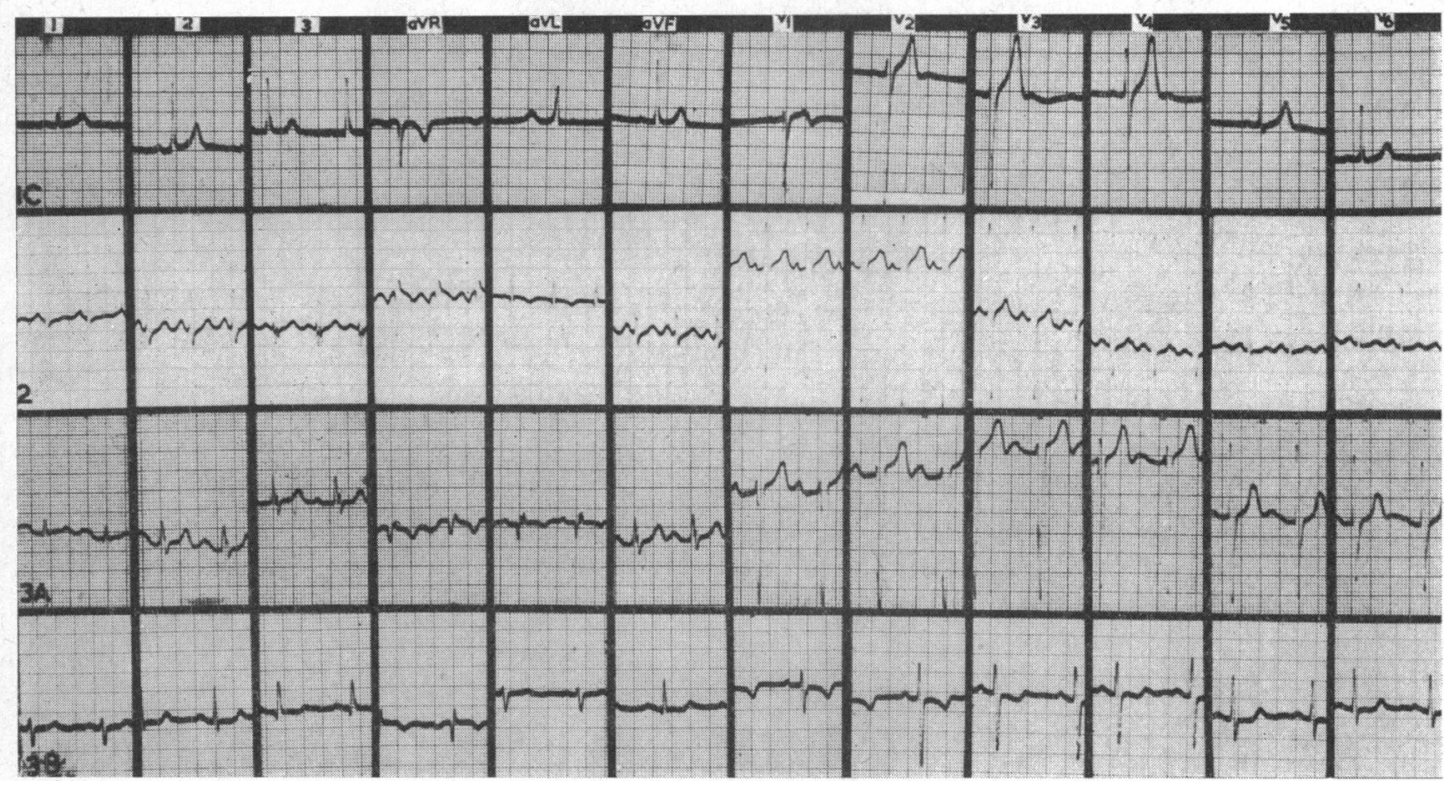

FIG. 6.-Selected cardiograms from 4 patients with Types 1C, 2, 3A, and 3B defects respectively. The first three show increase in voltage as the main abnormality. Right ventricular hypertrophy is not a feature in any, even in the fourth tracing from a patient with Type 3B defect (Eisenmenger's complex). Compare Fig. 8.

block. The mean frontal vector had a wide range within normal limits (Fig. 3), only 2 showing abnormal left axis deviation with patterns characteristic of endocardial cushion defect. The loop proceeded in either direction with equal frequency.

Type 1C. The cardiograms were virtually normal in 60 per cent of the patients: 4 showed right ventricular hypertrophy with an increased $\mathrm{R} / \mathrm{S}$ ratio in V1, and 5 had incomplete right bundle-

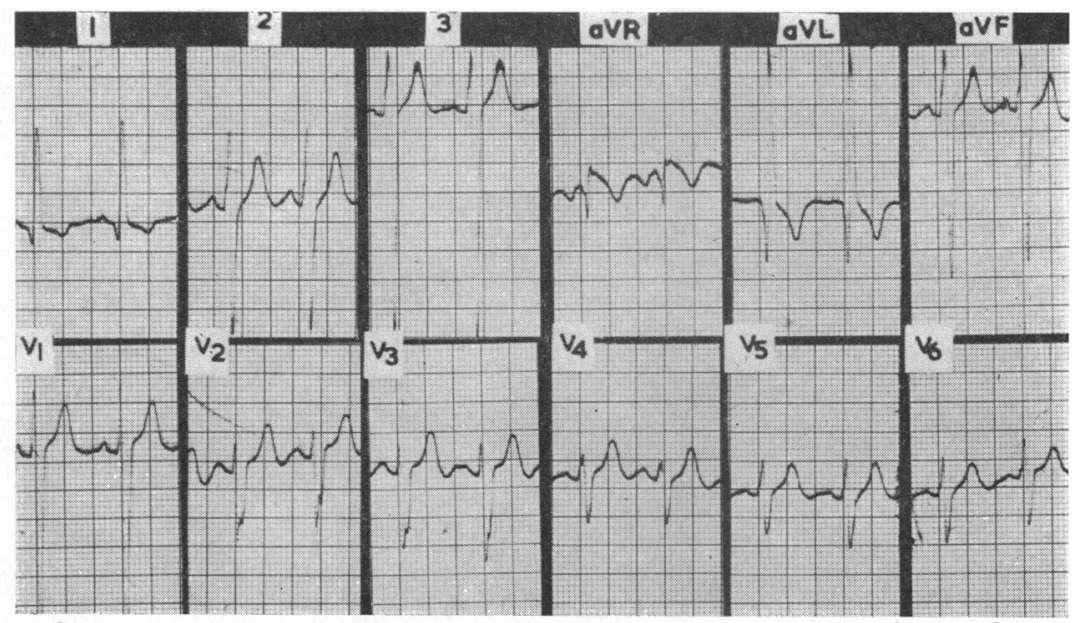

FIG. 7.-Except for the deep $\mathrm{S}$ waves in the chest leads, there is little evidence of right ventricular hypertrophy despite the fact that the patient has Type 3B VSD (Eisenmenger's complex), in fact left ventricular hypertrophy is present. The left axis deviation and counterclockwise loop would favour an endocardial cushion defect. 


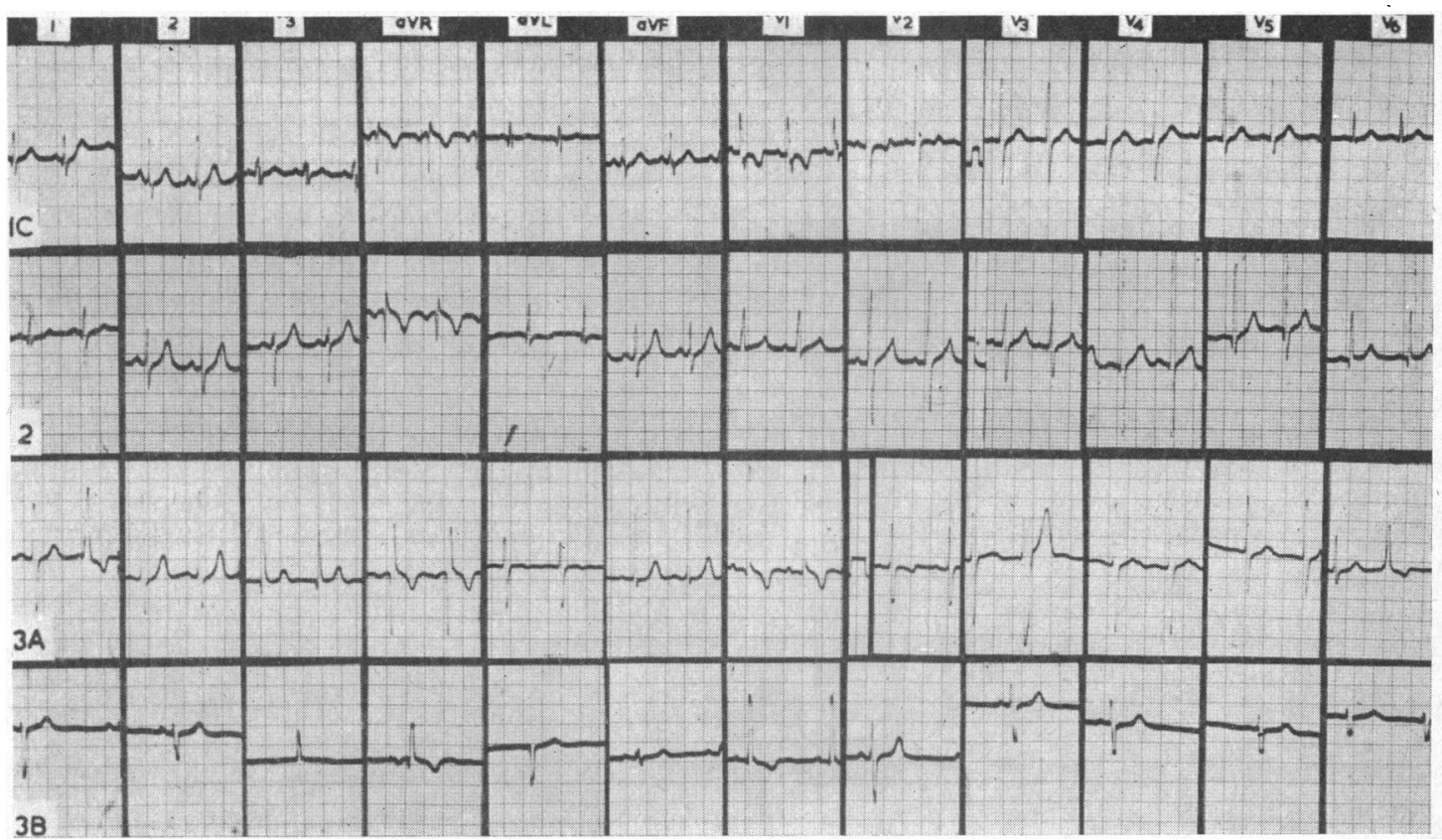

FIG. 8.- Selected cardiograms from 4 patients with Types $1 \mathrm{C}, 2,3 \mathrm{~A}$, and $3 \mathrm{~B}$ defects respectively. Right ventricular hypertrophy is present in all, most marked in 3B. Compare Fig. 6.

branch block. The voltage of RV6 was $26 \mathrm{~mm}$. or more in 4 patients (Fig. 5) with large Q waves, suggesting left ventricular hypertrophy in one. The mean frontal vector had a wide range within normal limits, only one showing right axis deviation $(+130)$. There were 5 patients with left axis deviation with counterclockwise loops as encountered in endocardial cushion defects. Anticlockwise loops were present in two-thirds of the tracings.

Type 2. Normal findings were encountered in only 3 of 25 tracings: 18 showed right ventricular hypertrophy often severe (with a qR in lead V1 in 3) and 4 incomplete right bundle-branch block (Fig. 3). The voltage of R V6 was $26 \mathrm{~mm}$. or more in 7 patients (Fig. 5) with large $Q$ waves in 6 suggesting left ventricular hypertrophy. Atrial hypertrophy, left or right, was present in 8 patients. The mean frontal vector had a wide range from +150 to -120 , right axis deviation +90 or more being present in most (Fig. 3). Left axis deviation was present in 2 patients. Anticlockwise loops were a little commoner than clockwise loops.

Type $3 A$. The cardiogram failed to show undoubted right ventricular hypertrophy in 6 patients, the $\mathrm{R} / \mathrm{S}$ ratio in $\mathrm{V} 1$ being less than 1 (Fig. 4). Right ventricular hypertrophy often severe (with a $\mathrm{qR}$ in V1 in 3) was present in 15 and incomplete right bundle-branch block in 3. The voltage of $R$ V6 was more than $26 \mathrm{~mm}$. in 9 of the 24 patients with large $Q$ waves in 5. Atrial hypertrophy, usually left, was present in 7 patients. The mean frontal vector had a wide range (Fig. 3) but most showed right axis deviation. One patient had the pattern associated with endocardial cushion defect. The loop was orientated in a clockwise direction more frequently than in a counterclockwise direction.

Type 3B. Clear-cut evidence of right ventricular hypertrophy was absent in 2 of the 21 patients (Fig. 6, 7), in one of whom the tracing was almost normal (Fig. 6): the other had a normal $r / S$ in V1 with deep $S$ waves across the præcordium. Three patients had incomplete right bundle-branch block, the remainder showing right ventricular hypertrophy, often severe (Fig. 8) with a qR complex in V1 in one. The voltage of R V6 was more than $26 \mathrm{~mm}$. in 2 patients with large $Q$ waves in 
2 (Fig. 5). The mean frontal vector was between +100 and +180 in all but one exceptional patient (Fig. 7) in whom the pattern was that of an endocardial cushion defect. The loop was orientated in a clockwise direction in all but three.

\section{RADIOLOGY}

The radiological findings are summarized in Table VII.

Type 1A. They were normal in all but one subject who had a cardiothoracic ratio (CTR) of 52 .

Type 1B. The radiological appearances were normal in the majority with a CTR of less than 50 in 70 per cent. The pulmonary vasculature was usually within normal limits. Upper lobe plethora, usually slight in amount, was noted in the straight x-ray films in 20 per cent, but increased hilar pulsation was noted in only 3 subjects. A right-sided aorta was noted once.

Type 1C. Cardiac enlargement was noted in two-thirds of the patients with a CTR above 50 per cent. It was difficult to be certain which chamber was chiefly responsible for this, but in most patients it was attributed to the left ventricle. The pulmonary arteries were usually normal, occasionally enlarged, and the aorta was generally passed as normal. Upper lobe plethora was noted in a quarter, never very great; and increased hilar pulsation on screening was also uncommon.

TABLE VII

RADIOLOGICAL FINDINGS

\begin{tabular}{|c|c|c|c|c|}
\hline & & Heart size (CTR) & Pulmonary artery & Plethora \\
\hline Type $1\left\{\begin{array}{l}\text { A } \\
\text { B } \\
\text { C }\end{array}\right.$ & $\begin{array}{l}\because . \\
\ddot{*}\end{array}$ & $\begin{array}{l}44(40-52) \\
49(37-64) \\
52(40-70)\end{array}$ & $\begin{array}{l}\mathbf{N} \\
\mathbf{N} \text { occas }+ \\
\mathbf{N} \text { occas }+\end{array}$ & $\begin{array}{r}\mathrm{N} \\
\mathrm{N} \text { to }+(20 \%) \\
++ \text { Occas } N(25 \%)\end{array}$ \\
\hline Type $2 \quad \ldots$ & .. & $62(49-76)$ & $\mathrm{N}$ to +++ & ++ to +++ \\
\hline & . . & $61(45-69)$ & + to +++ & + to +++ \\
\hline B & . & $55(40 \cdot 82)$ & $\mathrm{N}$ to ++++ & $\mathrm{O}-++$ \\
\hline
\end{tabular}

Type 2. Chest films were available in 20 patients and in all but one cardiac enlargement (with a CTR over 50) was present. In general the largest hearts were present in this group, right ventricular enlargement being readily recognizable in the majority. The main pulmonary arteries were enlarged sometimes considerably in two-thirds of the patients, increased hilar pulsations being noted in most of them on screening. Pulmonary plethora was noted in all, ranging from upper lobe involvement to plethora throughout both lung fields: pulmonary arterial pruning was absent. Left atrial enlargement was noted on screening but special radiological studies were not undertaken, so that the frequency cannot be analysed. Corrected transposition was noted in one patient.

Type $3 A$. Radiologically Types 2 and $3 A$ were indistinguishable. Only one of the 24 patients in this group failed to show cardiac enlargement (with a CTR of 45) and in almost all the right ventricle appeared to be enlarged. Recognition of biventricular enlargement radiologically is notoriously difficult, especially without special oblique views. The main pulmonary arteries were thought to be enlarged in all but one, often considerably so, with a striking hilar dance in many of those who were screened. Pulmonary plethora was noted in all, as in Type 2.

Type 3B. Chest films were available in 13 patients and in all but two cardiac enlargement (with a CTR of 50 per cent or over) was present. The hearts, however, were far less enlarged than in Types 2 and $3 \mathrm{~A}$, presumably because of systolic overload, compared with the systolic and diastolic overload present in the other types. It was thus more difficult to recognize right ventricular enlargement which was only identified in half the patients. Considerable, even aneurysmal, enlargement of the pulmonary arteries was the rule (with one exception) and clear-cut pruning was noted in 7. 


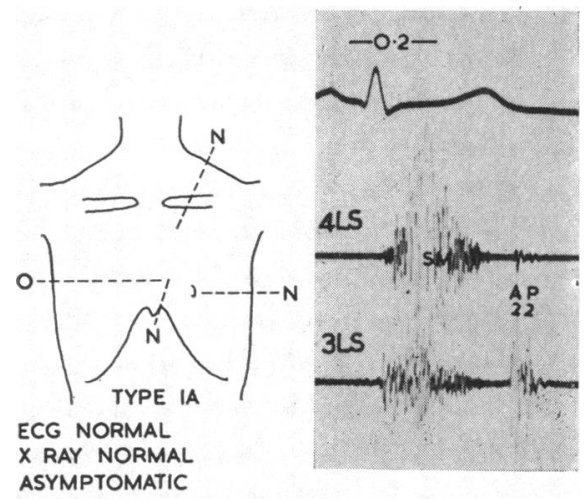

FIG. 9.-See text.

Pulmonary plethora was noted in 4 patients, 2 of whom had associated atrial septal defects. Increased hilar pulsations were noted in 2 subjects one of whom had gross pulmonary regurgitation. There was one exceptional case in a child of 4 years with gross cardiomegaly, right ventricular enlargement, and a CTR of 82 per cent.

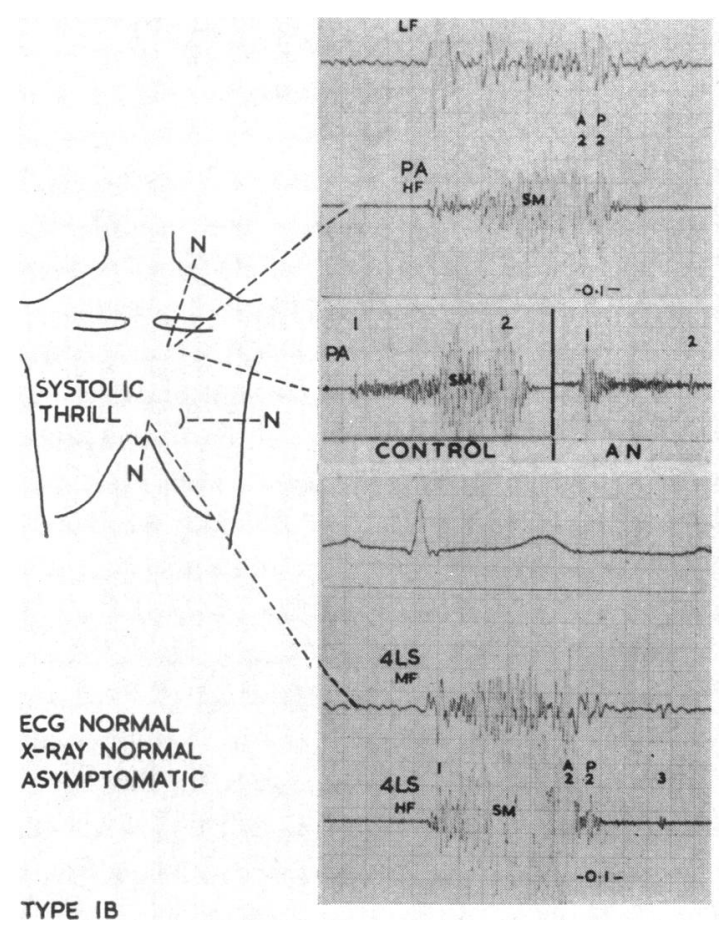

Fig. 10.-See text.

\section{Discussion}

Uncomplicated ventricular septal defect can be divided on hæmodynamic criteria into three main groups depending on the pulmonary arterial pressure and the pulmonary blood flow. These groups may be fairly accurately recognized at the bedside by careful attention to the findings on palpation and auscultation. The electrocardiogram; on the other hand, is far less reliable since the overlap is so wide (Fig. 3-8). The accuracy of radiology lies between the electrocardiogram and the bedside findings, providing one knows that the patient suffers from ventricular septal defect. Taking the clinical findings, cardiogram, and radiograph together the pre- and post-catheter assessments seldom differ.

Type 1A (Fig. 9). This is the least common variety. The only abnormal finding is a short systolic murmur, usually maximal at the fourth left intercostal space. The murmur begins with the first sound, is usually grade $3 / 6$ or less in intensity, has a crescendo in the first third of systole, and then softens rapidly. It behaves like a left-sided regurgitant murmur in response to vasoactive drugs. Normal pressures and flows are found on routine catheterization, special techniques being required to demonstrate the small ventricular shunt.

Type 1B (Fig. 10). This is the commonest variety of ventricular septal defect. Attention is drawn to the heart because of murmurs, the patient having no symptoms. On palpation the only abnormality is a coarse systolic thrill at the fourth left intercostal space. A loud (grade 4-5/6) pansystolic regurgitant murmur accompanies the thrill, there is a third sound at the apex, and usually no mid-diastolic murmur. The second sound has the normal intensity and is either normally or widely split. In one-fifth of the patients the murmur and thrill are maximal at the pulmonary area and if the second sound is also widely split the condition is indistinguishable from mild pulmonary stenosis. The response to vaso-active drugs is diagnostic. The cardiogram and radiograph are normal. 


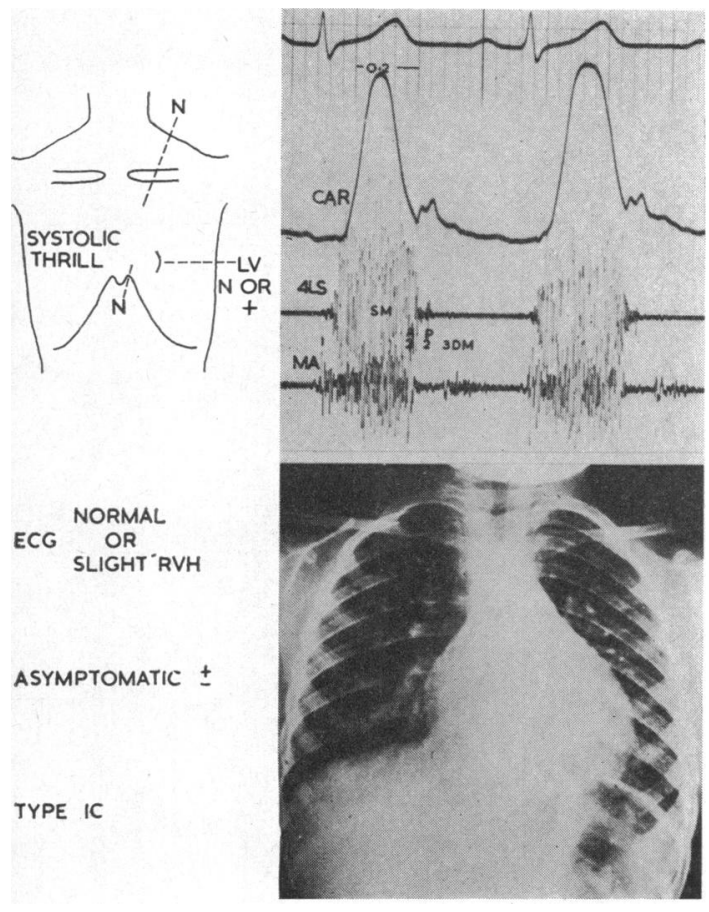

FIG. 11.-See text.

The pulmonary arterial pressure is normal and a small ventricular shunt $(<40 \%)$ is present on catheterization.

Type 1C (Fig. 11). Most patients have no symptoms but present with a loud (grade 4-5/6) murmur heard at an early age. On palpation a coarse systolic thrill at the fourth left intercostal space is always present with a normal or slightly displaced overactive left ventricular apex beat. The ventricular septal defect murmur is the same as that described in Type 1B but it is accompanied by a third sound and usually a mitral diastolic murmur at the apex. The intensity of the second sound is normal and the split normal or wide. The cardiogram is usually normal but right ventricular hypertrophy or incomplete right bundle-branch block may occur. Radiographs show cardiomegaly with moderate pulmonary plethora. The pulmonary arterial pressure is normal but a large ventricular shunt $(>40 \%)$ is present at cardiac catheterization.

Type 2 (Fig. 12). Attention is drawn to symptoms and murmurs at an early age. A central chest bulge is often associated with the clearly enlarged overactive heart. On palpation a coarse systolic thrill can be felt at the fourth left intercostal space in most patients, with an abnormally thrusting displaced overactive left ventricular apex beat. Right ventricular overload can be predicted by the lift over the outflow tract of the right ventricle and the palpable pulmonary second sound. A loud (grade 4-5/6) pansystolic regurgitant murmur is most commonly heard, though occasionally it appears to be shorter: it is maximal at the fourth left intercostal space. A third heart sound and easily audible mitral diastolic murmur can be heard at the apex. Of great significance is the normal or widely split second sound with moderate accentuation of the pulmonary component. The 


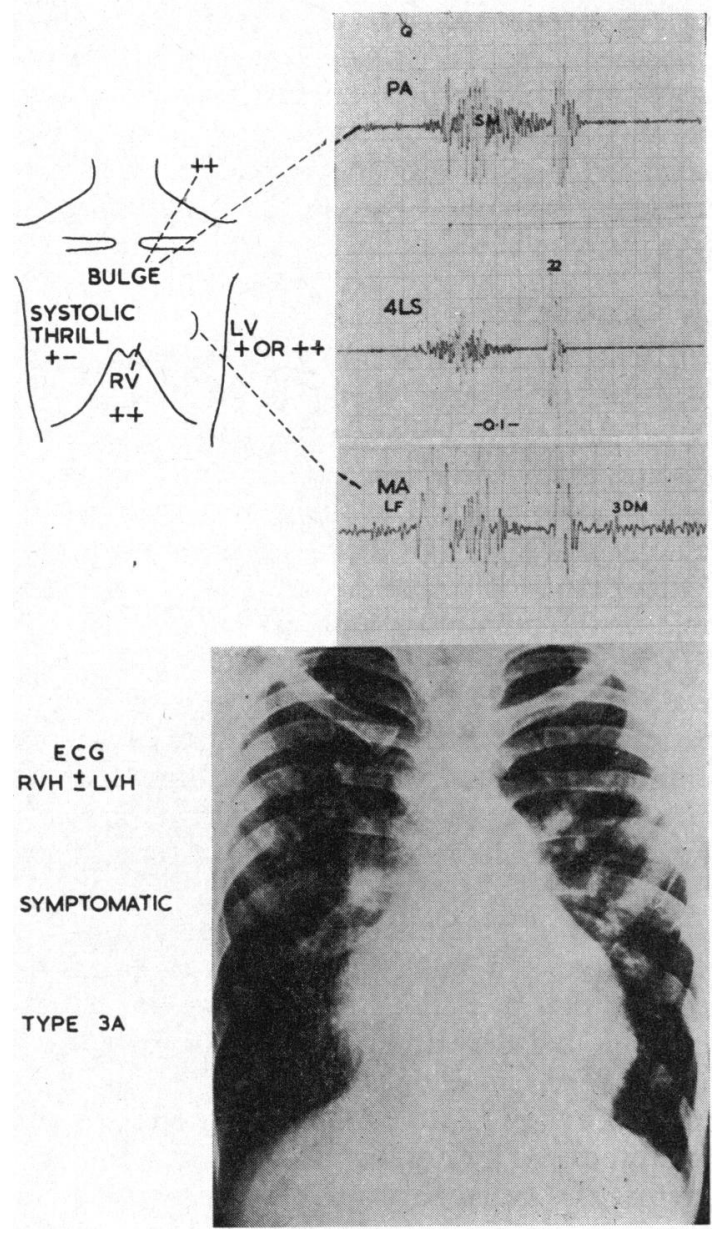

Fig. 13.-See text.

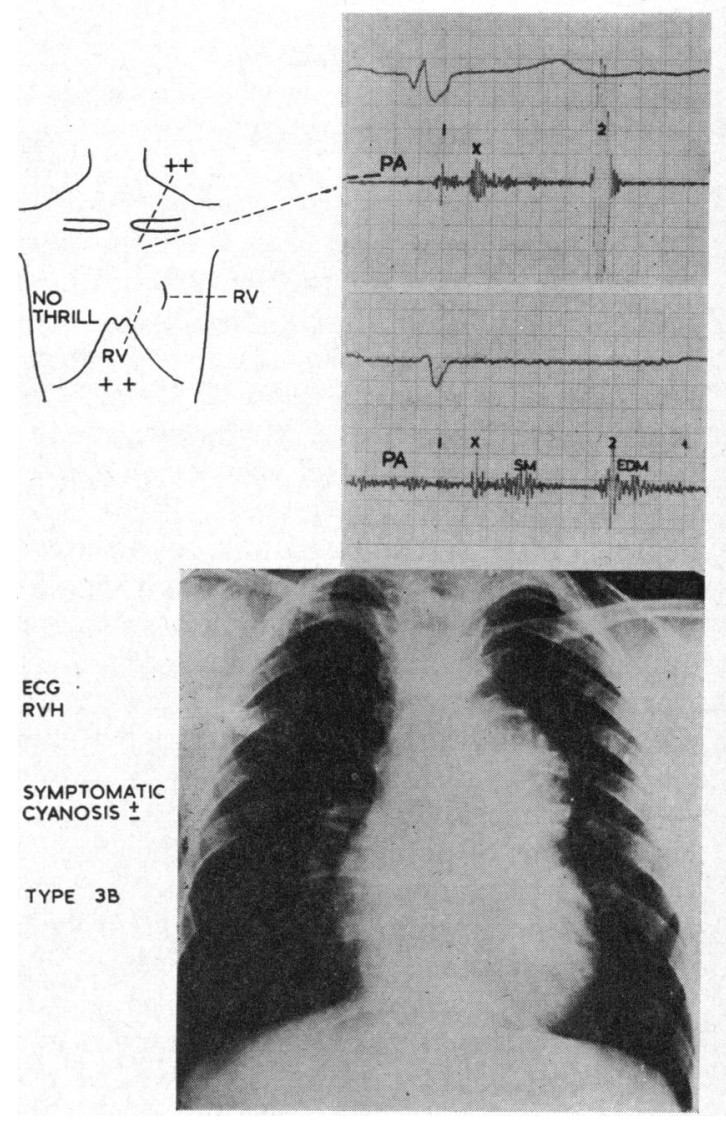

Fig. 14.-See text.

cardiogram shows right axis deviation with right ventricular hypertrophy or incomplete right bundle-branch block, and sometimes associated left ventricular overload can be detected. Radiologically considerable cardiomegaly and pulmonary plethora are present. The pulmonary arterial pressure is moderately raised with a large ventricular shunt $(>40 \%)$.

Type $3 A$ (Fig. 13). Patients in these groups present at an early age with symptoms and murmurs and are distinguished with difficulty from Type 2 . Thus, the physical signs, cardiogram, and radiological findings are very similar but the most important differentiating feature is the clinical evidence of severe pulmonary hypertension. The lift over the outflow tract of the right ventricle is more pronounced and the pulmonary valve closure is readily palpable. A systolic thrill is often absent and the systolic murmur is usually short and softer (grade 2-4/6). Most important of all is the single or narrowly split second sound which is much accentuated. The apical mid-diastolic murmur reflects the large left-to-right shunt and readily differentiates this condition from Type 3B. On cardiac catheterization a left-to-right shunt is present $(>40 \%)$ with more or less equal pulmonary arterial and systemic systolic pressures.

Type $3 B$ (Fig. 14). This condition is recognized more often because of symptoms and cyanosis than because of murmurs. On palpation the signs of pulmonary hypertension (right ventricular 
heave and pulmonary diastolic shock) are usually obvious without recognizable cardiomegaly and a systolic thrill is absent. There is a soft (grade $2 / 6$ ) or absent pulmonary systolic murmur, a pulmonary ejection click, frequently a pulmonary early diastolic murmur, and no mitral diastolic murmur. The second sound is accentuated and single. The cardiogram shows right ventricular hypertrophy indistinguishable from Types 2 and 3A. Radiologically, on the other hand, a smaller heart is present with much pulmonary arterial enlargement and peripheral pruning. On cardiac catheterization bidirectional ventricular shunts are present with a large increase in pulmonary arterial resistance.

\section{Pulmonary OUtFlow ObSTRuction}

The coexistence of pulmonary outflow obstruction, whether valvar or infundibular, gives rise to the biggest problem in bedside diagnosis. Furthermore, ventricular septal defect (VSD) with pulmonary outflow obstruction produces a spectrum of clinical syndromes as wide as that of isolated VSD itself. There are two variables, the septal defect and the outflow obstruction. As long as the latter offers less resistance than the systemic resistance, whether the VSD is small or large, a left-toright shunt will be present. If the stenosis is severe and the VSD small the condition mimics pulmonary stenosis with intact ventricular septum. If the stenosis is severe and the defect large, the hæmodynamic result depends on whether the systemic or the pulmonary outflow resistance is the greater. If the systemic resistance is the greater, VSD with pulmonary stenosis, results; if the pulmonary stenosis is the greater the result is Fallot's tetralogy. If they are balanced acyanotic Fallot's tetralogy results. Moreover, even in an individual patient, the hæmodynamic state is not static. A young infant may have the dynamics of a VSD with mild infundibular stenosis, but as time goes by progressive hypertrophy of the crista supraventricularis diminishes the left-to-right shunt, resulting in reduction in heart size, and ultimately the clinical picture of Fallot's tetralogy may emerge (Becu et al., 1961 ; Lynfield et al., 1961).

The practical clinical difficulty produced by the presence of pulmonary outflow obstruction is that the signs of pulmonary obstruction are added to those of the VSD. Difficulties do not arise when the obstruction is severe, since the clinical picture is that of Fallot's tetralogy or severe pulmonary stenosis with functionally intact ventricular septum, but they do arise when the pulmonary obstructive resistance is less than systemic, whether the VSD is small or large.

Pulmonary outflow obstruction may be associated with Type 1, 2, or 3A VSD, so that the signs produced by these septal defects are added to the signs produced by outflow obstruction, the latter being accentuated by the increased volume of flow across the pulmonary valve. The cardiogram and radiograph have little value in deciding whether pulmonary outflow obstruction is present or not. The most important clues are clinical, as discussed elsewhere (Vogelpoel et al., in preparation). The systolic thrill has a wide distribution extending along the left parasternal border from the pulmonary area to the fourth left intercostal space. Similarly the murmur is loud at both areas, often equally so, with wide splitting of the second sound. The intensity of the pulmonary component is usually normal or increased, an important point in differentiating this combination from isolated pulmonary stenosis. An apical diastolic murmur indicates a VSD in the absence of coincident mitral valve disease.

Cardiac catheterization is of course the only certain way of making this diagnosis. However, despite the presence of pulmonary outflow obstruction it is usually possible to tell whether the VSD is small or large.

Other Associated Defects. These fall outside the scope of this analysis. Certain conditions such as coarctation of the aorta, dextroversion, and aortic regurgitation can be readily recognized, but others such as patent ductus arteriosus, atrial septal defect, corrected transposition, and mitral valve disease are often unsuspected.

Ventricular Septal Defect in Infancy

This presents a special problem (Fyler et al., 1958) dependent on the progressive changes that normally occur in the pulmonary vasculature after birth. With large defects the pulmonary 
circulation is never separated from the systemic so that the subsequent picture will depend on what happens to the pulmonary vasculature and the outflow tract of the right ventricle. With small defects the normal progression of the thick-walled fotal pulmonary arteries to the dilated thin wall adult vessel takes place.

We have investigated very few patients in the infant group and then only when an infant was distressed. It may be that the clinical, cardiographic, and radiological criteria described do not apply to this particular age-group.

\section{Indications for Surgery in Ventricular SePtal Defect}

The indications for operation in ventricular septal defect have varied considerably not only with the passage of years but from centre to centre. This has mainly been due to ignorance of the natural history of the disease, and we do not know the fate of patients who have had ventriculotomy and a patch. Only recently has the relative frequency of natural closure of these defects been appreciated (Bloomfield, 1964; Evans, Rowe, and Keith, 1960; Harned and Peters, 1960; Nadas et al., 1961). Not only do small defects (Type 1A and B) close but even Type 3 defects may spontaneously close (Nadas et al., 1961). Usually this occurs in infants and young children, but closure may occur in later life even in middle age (Bloomfield, 1964).

In Fig. 15 our experience with operative treatment of VSD is shown. Operation should not be advised for patients with Type 1A and 1B defects. We have not done so even after cure of subacute bacterial endocarditis, though this is regarded as an indication by some (Kirklin and DuShane, 1963). Although the operative mortality in Type $1 \mathrm{C}$ should be almost zero we only advise operation if there are symptoms and the shunt is considerable, e.g. over 60 per cent. Patients in Type 3A or Type 2 are usually symptomatic and fail to thrive. Medical management is preferable up to the age of 3 (Lynfield et al., 1961; Nadas, Rudolph, and Gross, 1960). After this, if the patient is not doing well, operation is advised unless corrected transposition is present. We do not advise opera-

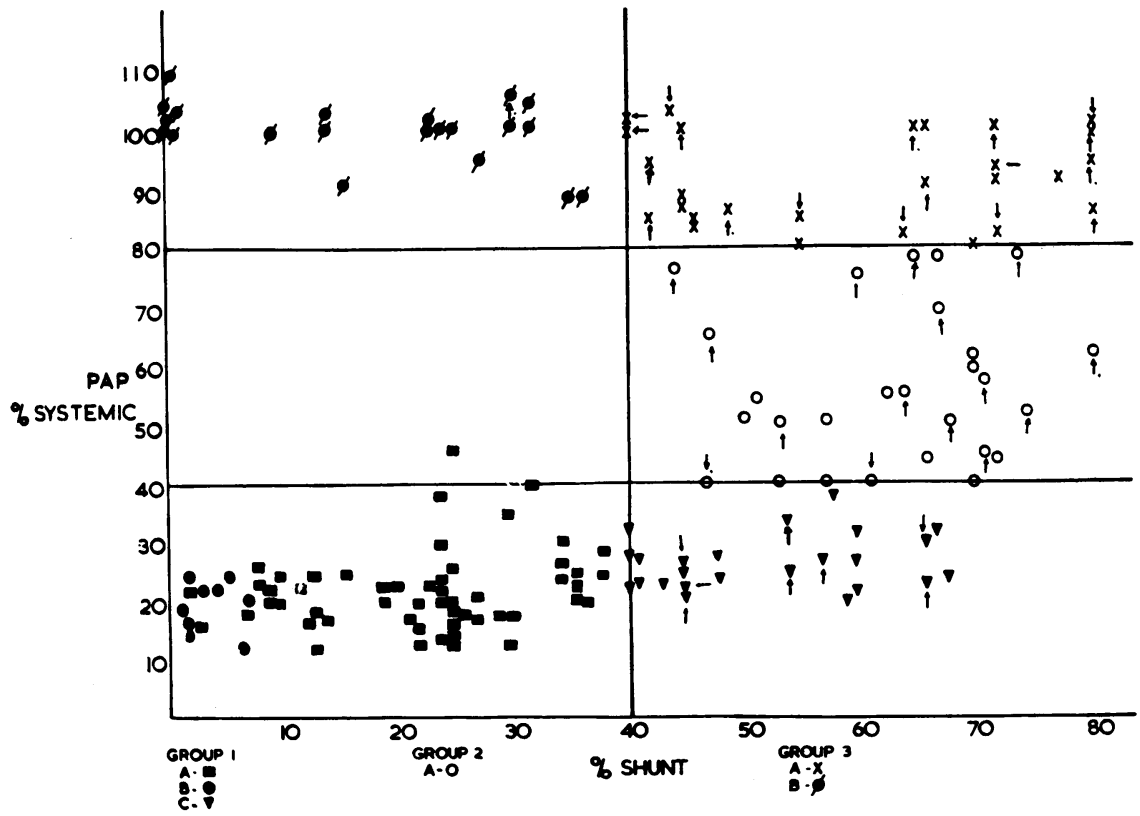

FIG. 15.-The patients who have been submitted to operation are shown by an arrow. Patients with Type 2 and $3 A$ defects are clear candidates for operation. Patients with Type 1C defects should be advised operation only when the shunts are very large. The 3 patients with relatively small shunts were operated upon early in our series. The one patient with Type 3B defect, operated on elsewhere, died. The deaths (7) are indicated by the dot next to the arrow. 
tion in Type 3B even though closure may be successfully achieved, since we believe the patient is left with severe chronic pulmonary hypertension. The natural history of the latter condition is probably not better than that of the original disease itself (Bloomfield, 1964). We have observed that patients with Type 3B defects live a reasonably comfortable life for many years and our oldest patient is now over 50 .

\section{SUMMARY}

Two hundred patients with ventricular septal defects have been catheterized: in 40 of them pulmonary outflow tract stenosis (valvar or infundibular) was present. This report deals with the 160 patients without pulmonary stenosis.

From the data obtained by cardiac catheterization ventricular septal defects can be subdivided into three types. In Type 1 the pulmonary systolic pressure is more or less normal, being less than 40 per cent of the systemic systolic pressure. In Type 3 the two systolic pressures are more or less equal (P.S.P./S.S.P. $>80 \%$ ). Type 2 falls between 1 and 3 .

Type 1 can be divided into Types $1 \mathrm{~A}$ and $1 \mathrm{~B}$ with a shunt less than 40 per cent, $\mathrm{A}$ and $\mathrm{B}$ being distinguished by the character of the systolic murmur, and Type 1C with a shunt of more than 40 per cent. Type 3 can be divided into $3 \mathrm{~A}$ with a left-to-right shunt greater than 40 per cent and Type 3B with a bidirectional or dominant right-to-left shunt.

A fairly accurate assessment of the hæmodynamic state in ventricular septal defect can be made after careful clinical examination when particular attention is paid to palpation and auscultation.

The electrocardiogram by itself is least helpful in assessing pressure flow relationships. Radiology on the other hand is very useful, once the diagnosis of ventricular septal defect has been made.

Clinical examination together with the electrocardiogram and radiograph usually provide an accurate hæmodynamic diagnosis at the bedside.

We wish to thank our medical and pædiatric colleagues for referring patients, the Cardio-Surgical Unit under Professor C. N. Barnard for surgical confirmation, and the Superintendent of Groote Schuur Hospital, Dr. J. G. Burger, for permission to publish. Our special thanks are due to Mr. L. W. Piller, Miss S. Joseph, and the technical staff of the catheterization laboratory and Sister J. Abbott for nursing help. We thank the Council for Scientific and Industrial Research and City Council of Cape Town for their continued financial support.

\section{REFERENCES}

Becu, L., Ikkos, D., Ljungqvist, A., and Rudhe, U. (1961). Evolution of ventricular septal defect and pulmonary stenosis with left to right shunt into classic tetralogy of Fallot. Amer. J. Cardiol., 7, 598.

Bloomfield, D. K. (1964). The natural history of ventricular septal defect in patients surviving infancy. Circulation, 29, 914.

Evans, J. R., Rowe, R. D., and Keith, J. D. (1960). Spontaneous closure of ventricular septal defects. Circulation, 22, 1044.

Fyler, D. C., Rudolph, R. M., Wittenborg, M. H., and Nadas, A. S. (1958). Ventricular septal defect in infants and children: a correlation of clinical, physiologic and autopsy data. Circulation, 18, 833 .

Harned, H. S., and Peters, R. M. (1960). Spontaneous closing of ventricular septal defects: Two case reports. Circulation, 22, 760.

Kirklin, J. W., and DuShane, J. W. (1963). Indications for repair of ventricular septal defects. Amer. J. Cardiol., $12,75$.

Lynfield, J., Gasul, B. M., Arcilla, R., and Luan, L. L. (1961). The natural history of ventricular septal defects in infancy and childhood. Amer. J. Med., 30, 357.

Nadas, A. S., Rudolph, A. M., and Gross, R. E., (1960). Pulmonary arterial hypertension in congenital heart disease. Circulation, 22, 1041.

- - Scott, L. P., Hauck, A. J., and Rudolph, A. M. (1961). Spontaneous functional closure of ventricular septal defects. New Engl. J. Med., 264, 309.

Schrire, V. (1963). Experience with congenital heart disease at Groote Schuur Hospitai, Cape Town. S. Afr. med. J., 37, 1175 .

Vogelpoel, L., Nellen, M., Swanepoel, A., and Schrire, V. (1959). The use of amyl nitrite in the diagnosis of systolic murmurs. Lancet, $2,810$.

- , and Schrire, V. (1955). The role of auscultation in the differentiation of Fallot's tetralogy from severe pulmonary stenosis with intact ventricular septum and right-to-left interatrial shunt. Circulation, 11, 714. $--, \frac{1}{\text { with and without pulmonary stenosis. In preparation. }}$

$-,-\ldots,-$, and Swanepoel, A. (1962). Variations in the response of the systolic murmur to vasoactive drugs in ventricular septal defect, with special reference to the paradoxical response in large defects with pulmonary hypertension. Amer. Heart J., 64, 169. 